\title{
ROMEU E JULIETA POR OUTROS OLHARES
}

\author{
CARINI de FÁTIMA RIBEIRO HINNAH ${ }^{1}$ \\ carinih@ibest.com.br
}

\begin{abstract}
The present work deals with the production of new versions based on Romeo and Juliet by William Shakespeare. Besides, it discusses the parody and intertextuality concepts, based on analyze of some theorists. The knowledge about theory and practice because it was a textual production work, it proves the importance of using these recourses of writing on the composition of texts with students on third year of high school. For development of work, it was carried out a bibliographical research as methodology support and the use of parodies as source of confirmation about the analysis's items.
\end{abstract}

KEYWORDS: Shakespeare. Parody. Writing. Intertextuality.

\section{INTRODUÇÃO}

A Literatura é uma das mais ricas formas de arte, seja em sua forma oral ou escrita. E como arte, se faz reflexiva. Sendo assim, o trabalho de pesquisa "Romeu e Julieta por outros olhares" procurou oferecer aos alunos do terceiro ano do Ensino Médio, turma 301, da E.E.E.M. José de Anchieta, do município de Panambi, no segundo semestre de 2007, a oportunidade de conhecer e produzir paródias baseadas na obra Romeu e Julieta, de William Shakespeare.

Diante dos temas principais da obra, amor proibido e rivalidade entre famílias, a turma foi convidada a desenvolver novas versões, utilizando o efeito reflexivo da literatura, bem como questões sociais contemporâneas em relação àquelas distantes temporalmente. O objetivo, que constituiu o corpus do Trabalho de Conclusão de Curso, foi verificar se os alunos, ao parodiar o texto de Shakespeare, deixariam ou não aparecer seu modo de pensar, favorável ou não, sobre os temas tratados.

O trabalho apresenta a síntese da obra Romeu e Julieta, a sinopse do filme Shakespeare apaixonado, também utilizado como recurso de pesquisa, e cita teorias sobre paródia e intertextualidade recorrendo a alguns pesquisadores como Carvalhal, Alves, Heliodora, Hutcheon, entre outros.

O primeiro capítulo trata de aspectos sobre a obra parodiada, sobre o escritor William Shakespeare e também acerca do filme utilizado em sala de aula.

1 Aluna do Curso de pós-graduação da UNICRUZ 
Já no segundo capítulo, o estudo conceitua paródia e intertextualidade, questões teóricas que deram sustentação à análise do que foi produzido.

O último capítulo fez a relação necessária entre teoria e prática, avançando para uma apreciação individual de cada uma das paródias.

A parte conclusiva retoma informações apresentadas ao longo da investigação bibliográfica e prática para apresentar as constatações finais.

\section{DRAMARTUGIA: TRAGÉDIA AMOROSA ROMEU E JULIETA, POR WILLIAM SHAKESPEARE}

O clássico da Literatura Inglesa, Romeu e Julieta de William Shakespeare, além de ser conhecido mundialmente, ainda hoje deixa comovidas e impressionadas as pessoas que o lêem. Isto porque a história parece surreal para a atualidade.

Porém, sabe-se que temas como amor proibido e rivalidade entre famílias são tão atuais como eram na época em que o autor escreveu. Amar já é um assunto delicado. Amar o filho ou a filha de uma família inimiga é um sinal inconfundível de que grandes confusões virão.

Shakespeare transformou-se em um dos maiores dramaturgos de seu tempo por colocar em cena as mazelas, os erros, os medos, a ironia, o egoísmo, enfim, a personalidade humana. $O$ enredo de suas obras velava suas reais intenções: falar, criticar, discutir a vida e seus problemas; o ser humano e suas limitações. Heliodora (1998, p. 240) procura explicar de que maneira Shakespeare conseguia atingir seu público, sendo que não dispunha de recursos utilizados, por exemplo, pelos romancistas:

\footnotetext{
Dois pressupostos são indispensáveis: o primeiro é o de que Shakespeare tinha alguma coisa a dizer quando escrevia uma peça; o segundo é o de que o que ele tinha a dizer não era pura e simplesmente contar uma história; pois se assim fosse é provável que tivesse escrito enredos originais. Usando material encontrado nas mais variadas fontes, Shakespeare nos dá, em sua obra, sobejos exemplos da singela definição de arte que Richard Southern sugere seja aceita para facilitar a vida de todo o mundo: arte é quando se faz uma coisa mas se quer dizer outra, não no sentido de um paradoxo mas de uma sobrecarga de significado, que permite ao que é escrito, por exemplo, transmitir bem mais do que seu mero conteúdo de dicionário.
}

Romeu e Julieta representa muito bem a definição de arte conforme citado, pois aparenta ser apenas uma história trágica de amor, no entanto é uma reprodução social do momento em que vivem os personagens. Assim como na maioria de suas obras, Shakespeare utiliza-se do teatro para divulgar sua perplexidade frente às atitudes do mundo. Para Heliodora (1998, p. 42), quem lê a peça fica tão envolvido que acaba fazendo uma análise mais superficial e deixando alguns pontos importantes sem discussão: 
Romeu e Julieta é de tal modo envolvente, apaixonante que ao menos dois aspectos são normalmente esquecidos: por um lado, até que ponto a linguagem é excessiva em momentos de crise; por outro, o fato de a obra não ser (ou pelo menos não ser só) uma história de amor mas, sim, um sermão sobre os males da guerra civil, Romeu e Julieta compram com suas vidas a paz entre suas duas famílias, que viviam em luta gratuita e danosa para a comunidade. Está será, talvez, a primeira tragédia comunitária, pois quem passa pelo doloroso aprendizado trágico são as famílias e não os jovens amantes, vítimas destruídas porque se amam em um mundo de ódio.

A morte trágica dos jovens, em função de seu amor proibido, acaba por selar a paz entre as famílias, que pagaram um preço realmente alto por viverem de maneira ignorante durante anos. Ainda que longe no tempo, o conflito de Romeu e Julieta faz uma ponte com os problemas da família contemporânea. Amores proibidos ainda estão na "moda". São especulações, são notícias, são também tragédias.

Portanto, comparar os conflitos familiares e sentimentais da peça com as atitudes das pessoas de hoje não é mera coincidência, já que para Carvalhal (1998, p. 6) comparar é um procedimento que faz parte da estrutura de pensamento do homem e da organização da cultura. Por isso tudo, a atividade proposta aos alunos configurou-se na reescrita de Romeu e Julieta a partir da visão de mundo e de conceitos já pré-estabelecidos por cada um deles. Esse trabalho veio confirmar a repetição da história não apenas como repetição, mas como re-invenção. Carvalhal (1998, p. 53-54) discorre sobre esse tópico:

\footnotetext{
Toda repetição está carregada de uma intencionalidade certa: quer dar continuidade ou quer modificar, quer subverter, enfim, quer atuar com relação ao texto antecessor. A verdade é que a repetição, quando acontece, sacode a poeira do texto anterior, atualiza-o, renova-o e (por que não dize-lo?) o re-inventa.
}

Esse "re-inventar" acontece através do olhar crítico do aluno em relação aos acontecimentos da tragédia. Quem escreve coloca um pouco da sua personalidade no texto, quem re-inventa uma história quer opinar sobre ela, que dizer o que pensa.

As versões finais dos alunos, re-invenções da tragédia de amor mais conhecida no mundo, são a prova da capacidade que o alunado tem de compartilhar com os demais seu conhecimento de mundo, sua moral, seus costumes, suas idéias.

Além dessa atividade de reescrita, os alunos também tiveram a oportunidade de conhecer um pouco mais acerca do trabalho de Shakespeare, que além de escrever, também representava suas peças. O filme Shakespeare in love (Shakespeare apaixonado) foi assistido e comentado pela turma, proporcionando a manifestação de diferentes opiniões sobre a obra cinematográfica.

Para Duarte (2002, p. 67) a relação da escola com o cinema é muito importante, pois o filme é uma ferramenta de transmissão de conhecimento: 
Saber como o cinema atua nos leva a admitir que a transmissão/produção de saberes e conhecimentos não é prerrogativa exclusiva da escola (embora ele tenha um importante papel a desempenhar nesse processo), mas que acontece também em outras instâncias de socialização. Pensar o cinema como uma importante instância "pedagógica" nos leva a querer entender melhor o papel que ele desempenha junto àqueles com os quais nós também lidamos, só que em ambientes escolares e acadêmicos.

Outra questão a considerar: se admitirmos que a significação de filmes é gradual e articulada aos modos de ver do grupo de pares e aos diferentes tipos de discursos produzidos em torno dos filmes, faz sentido pensar que é possível "ensinar a ver". Isso implica valorizar o consumo de filmes, incentivar discussões de diferentes interpretações, trazer a experiência com o cinema para dentro da escola.

O fato de o professor utilizar filmes como recurso audiovisual para sua aula deve estar centrado, principalmente, na idéia de que o filme servirá como fonte para as discussões às quais o educador pretende chegar. Não se vai à sala de vídeo da escola com objetivo de "passar um filme" para que a aula "passe" mais rápido. 0 aluno precisa desenvolver a competência de ler de maneira diferente, através de imagens, tornando-se apto à crítica e sendo capaz de definir sua opinião acerca da história ficcional filmada. Para tanto, é imprescindível que o mestre tenha noção não apenas sobre a reflexão que pretende conduzir ao final do filme, mas também em relação aos elementos que constituem estruturalmente a obra. Duarte (2002, p. 88) retrata, em sua obra, o valor existente nos longas-metragens:

[...] a escolha dos filmes que são exibidos em contexto escolar dificilmente é orientada pelo que se sabe sobre cinema, mas, sim, pelo conteúdo programático que se pretende desenvolver a partir ou por meio deles. Nesse caso, o filme não tem valor por ele mesmo ou pelo que representa no contexto da produção cinematográfica como um todo; vale pelo uso que podemos ou não fazer dele em nossa prática pedagógica.

Portanto, apreciar filmes pode ajudar tanto os professores como os alunos. Para os primeiros é mais uma forma de trabalhar a literatura aproximando-a do universo cultural dos alunos e para estes é uma chance de aprender por outros meios, encontrando na escola um lugar onde as metodologias de trabalho estão presentes.

Tanto se pode descobrir novos saberes a partir da observação das imagens de um filme que os alunos do terceiro ano salientaram, na discussão final, a proibição de atuar em peças teatrais, imposta às mulheres da época, marca característica do teatro elisabetano. Além disso, os espectadores salientaram sobre a linguagem expressamente poética usada por Shakespeare em suas peças e os temas universais referidos nas mesmas.

Como já mencionado, os alunos perceberam algumas características importantes sobre a representação das peças, o que é confirmado por Heliodora (1998, p. 06). Segundo ela, Elizabeth I levou em torno de trinta anos de trabalho para colocar a Inglaterra em um período de equilíbrio estável, o que proporcionou a produção do, então chamado, teatro elisabetano. 
De acordo com Magaldi (2000, p. 7), na terminologia dos logradouros cênicos da Grécia, teatron correspondia à platéia, anteposta à orquestra e envolvendo-a como três lados de um trapézio ou um semicírculo. Essa definição grega não sofreu mudanças consideráveis ao longo dos tempos, pois para Heliodora $(1998, \mathrm{p} 15), o$ teatro elisabetano herdou uma grande parte de suas convenções do ingênuo teatro medieval, quando em cima de seu palco sobre rodas um ator dava uns poucos passos e ia de uma cidade para outra.

Já antes da era elisabetana, a arte dramática também impunha algumas características entre os ingleses. Heliodora (1998, p. 06) discorre com propriedade acerca desse episódio:

\begin{abstract}
Em 1576, portanto aproximadamente dez anos antes do reconhecido momento da explosão da nova dramaturgia elisabetana, Londres ganha seu primeiro teatro permanente, que fixou a forma do palco nascido das carroças ambulantes da Idade Média: sem aquele palco despojado, projetado para o meio do público, com várias entradas e saídas, com suas áreas separadas de palco exterior, interior e superior, que podiam ser usadas em conjunto sempre que o autor assim o quisesse; sem aquele espaço cênico a céu aberto, sem cenografia, dependendo da palavra do poeta para estabelecer quando e onde estavam ou existiam aqueles personagens, ou se desenrola aquela ação, [...].
\end{abstract}

A autora (1998, p. 09) também faz referência ao amadurecimento de Shakespeare, como indivíduo e artista, já que [...] o teatro elisabetano existiu em função de sua linguagem poética, capaz de transformar aquele espaço cênico fixo, neutro e vazio em qualquer coisa que o poeta tivesse capacidade para criar por meio da palavra, particularidade apreciada pelos alunos espectadores do filme Shakespeare in love.

Por fim, de acordo ainda com Heliodora (1998, p. 11), é possível afirmar que o fato de Shakespeare ter sido poeta foi essencial para sua passagem extraordinária pela dramaturgia elisabetana, sendo visível, em algumas de suas peças, o exagero em seu versejar.

\title{
SÍNTESE DE ROMEU E JULIETA E SINOPSE SHAKESPEARE IN LOVE
}

A obra Romeu e Julieta, de William Shakespeare, escrita em 1594/1595 conta uma história de amor trágico entre dois jovens provenientes de famílias rivais. $O$ enredo, ambientado em Verona, Itália, por volta do ano 1500, é uma prova da qualidade dos escritos de Shakespeare, já que evidencia as lutas de espada, o disfarce, os equívocos, a tragédia, o humor e a linguagem da paixão, o que simbolizam, no seu conjunto, o amor verdadeiro.

Além da obra escrita Romeu e Julieta, os alunos tiveram também a oportunidade de saber um pouco mais sobre a história do escritor e das questões sociais em que ele estava inserido a partir da análise do enredo do filme Shakespeare in love ou, em língua portuguesa, Shakespeare apaixonado.

Esta produção cinematográfica, gênero comédia romântica, foi produzida no ano de 1998 e dirigida por John Madden. No filme, William Shakespeare precisa escrever uma nova peça de teatro, uma história de amor com fim trágico, mas está sofrendo 
um bloqueio e somente uma musa inspiradora poderá ajudá-lo. Ao se apaixonar por Lady Viola, ele volta a ter inspiração e escreve a peça Romeu e Julieta.

Além disso, o filme retrata alguns aspectos da sociedade da época como, por exemplo, a proibição às mulheres de atuarem em peças de teatro, fazendo com que a personagem Lady Viola precise usar um disfarce masculino para fazer parte da trupe.

\title{
RECURSOS DE ESCRITA
}

Antes da exposição de qualquer conceito sobre paródia e intertexto, é preciso salientar a importância desses recursos de escrita para a literatura contemporânea. A utilização de histórias já publicadas como eixo para a produção de novas versões se tornou comum e bonita. Parodiar não significa plagiar, ao contrário, é uma forma de valorizar o que já existe, de agregar à base pré-existente valores sócio-culturais, religiosos, políticos, enfim, é caracterizar, é modernizar a partir de novos temas. Reis (1997, p. 398-399) explica acerca do assunto:

\begin{abstract}
Pela sua natureza e especificidade, as dominantes temáticas que se afirmam em certos momentos da evolução literária, ilustram sobretudo a componente axiológica dos períodos literários, quer dizer, instituem valores, postulam comportamentos ético-culturais, esboçam até tendências afectivas. Por isso, Serge Doubrovsky escreveu que "o tema, noção-chave da crítica moderna, não é senão a coloração afetiva de toda a experiência humana, ao nível em que essa experiência envolve as relações fundamentais da existência, isto é, a maneira particular como cada homem vive a sua relação com o mundo, com os outros e com Deus".
\end{abstract}

Com essa citação se pode confirmar a idéia de que a paródia e o intertexto são ferramentas que permitem ao autor tematizar uma nova versão a partir da compreensão particular que ele tem do mundo.

\section{PARÓDIA}

Paródia é a utilização de um texto (música, teatro, crônica, conto, etc.) como base para uma reescrita, na maioria dos casos, hilária. Vê-se bem o uso desta técnica entre os alunos de ensino fundamental e médio, que, orientados pelos professores, constroem textos estilizados sobre diversos assuntos. Geralmente estes alunos modificam letras de músicas e mantém apenas as melodias para as novas versões.

Ainda nas escolas, sabe-se que histórias clássicas como Chapeuzinho Vermelho, Romeu e Julieta, Rapunzel, entre outras, são parodiadas, ou seja, os alunos reescrevem a história modificando o ambiente, o tipo de narrador, as ações das personagens, enfim, o enredo; mas preservam a essência da história, o que será o elo de ligação entre as duas: clássica e paródia.

Hutcheon (1989, p. 48) define paródia com esta frase: A paródia é, na sua irônica transcontextualização e inversão, repetição com diferença. Pois bem, essa definição se aplica perfeitamente às condições de produção tanto dos alunos como de famosos parodiadores. Os textos, frutos da ação de parodiar, nada mais são que 
idéias repetidas de outros textos, porém, alteradas como forma de exposição de novas opiniões.

Sendo a paródia uma imitação, geralmente cômica e muitas vezes irônica de uma composição literária, vale dizer que o contexto social no qual está inserido o parodiador servirá como sugestão para a adaptação da obra original e que, provavelmente, será de fácil notoriedade. A paródia atual é livre, desenvolve temas diversos, não tem preocupação com a forma. Para Hutcheon (1989, p. 105) o período pós-moderno tem testemunhado uma proliferação da paródia como um dos modos de auto-referência estética positiva, bem como de escárnio conservador. $\mathrm{O}$ que confirma a liberdade do parodiador.

Segundo Alves (1990, p. 44), desenvolver uma paródia consiste em um objetivo específico:

[...] é fácil perceber na paródia uma finalidade exclusivamente literária, dada sua função crítica. Na verdade, a paródia propõe criar textos a partir de textos velhos, ou anteriores. Só por isso já exerce com bastante vigor sua função marcadamente crítica. Explica-se: ao remeter a outro ou a outros textos, recorda constantemente o caráter literário da leitura proposta. Assim, sua função especular é exercida no momento em que, ao reproduzir o modelo, inverte-lhe a imagem, podendo distorcêla ou deformá-la com maior ou menor intensidade; como prolongamento, ela se propõe aprofundar determinados aspectos abordados pelo modelo.

Esta demarcação permeia um olhar atual sobre a paródia. No entanto, sabe-se que muito se discutiu até que se chegasse a este significado. Hutcheon (1989, p. 47-48) esclarece alguns pontos sobre a origem do termo paródia:

\begin{abstract}
A vasta literatura sobre a paródia em diferentes épocas e lugares torna evidente que o seu sentido muda. [...] A maioria dos teóricos da paródia remontam a raiz etimológica do termo ao substantivo grego parodia, que quer dizer "contra-canto", e ficam por aí. Se olharmos mais atentamente para essa raiz obteremos, no entanto mais informação. A natureza textual ou discursiva da paródia (por oposição à sátira) é evidente no elemento odos da palavra, que significa canto. O prefixo para tem dois significados, sendo geralmente mencionada apenas um deles - o de "contra" ou "oposição". Desta forma, a paródia torna-se uma oposição ou contraste entre textos. Este é, presumivelmente, o ponto de partida formal para a componente de ridículo pragmática habitual da definição: um texto é confrontado com outro, com a intenção de zombar dele ou de o tornar caricato.
\end{abstract}

Para além das definições, é preciso reforçar o papel construtivo da paródia na literatura, que permite o confronto de textos a partir do confronto situacional do parodiador. Apesar desse caráter contributivo, a paródia nem sempre foi considerada importante por todos os seus estudiosos. Para alguns, a produção de novas versões não era regra de contribuição para o enriquecimento literário. Hutcheon (1989, p. 14-15) bem discorre sobre essa visão de repulsa:

A paródia precisa de quem a defenda: tem sido designada de parasitária e derivativa. A famosa aversão, para não dizer desprezo, de Leavis pela paródia 
baseava-se na sua crença de que aquela era o inimigo filisteu do génio criativo e da originalidade vital (Amis 1978, xv). Estes termos dão uma idéia de modo como tem sido denegrido um género que permeia toda a arte de nosso século. Alguns críticos rejeitam aquilo que vêem como uma sobreposição feita pela paródia de uma ordem externa numa obra que se presume ser original se se quiser que tenha valor (Rovit 1963, 80). O que se torna claro com esse tipo de ataques é a força subsistente de uma estética romântica que aprecia o génio, a originalidade e a individualidade. Nesse contexto, a paródia tem forçosamente de ser considerada, quando muito, um género muito menor. No entanto, desde a valorização por Eliot do "sentido histórico" e, completamente da atenção dada pelos formalistas (pela Nova Crítica, pelo estruturalismo) ao texto, ainda que muito diferentes, temos testemunhado um interesse renovado pelas questões de apropriação e até de influência textual.

É correto afirmar que a evolução, seja de uma palavra ou conceito, perpassa muitos momentos históricos, por onde vai agregando sentido a partir do social. Se em tempos anteriores a paródia era tida como uma devassa em textos originais e individuais, atualmente é considerada apenas uma reformulação literária, desconfigurando a imagem de destruição que ora adquirira. Ainda para Hutcheon (1989, p. 53), a visão que ela tem de paródia como imitação com diferença crítica agrega-se ainda mais à idéia geral da paródia como inscrição de continuidade e mudança.

Após tantas contradições, a paródia hoje é muito utilizada e defendida. Cada vez mais se encontram textos parodiados de obras clássicas, mudando o ambiente e transportando a base do enredo para um novo cenário, com outras mazelas e virtudes. Além disso, a paródia como instrumento de trabalho nas salas de aula, capacita os alunos, dando aos mesmos a oportunidade da recriação, o que os possibilita utilizar o imaginário, o sonho, a fantasia.

\section{INTERTEXTUALIDADE}

Antes de analisar teoricamente o termo "intertextualidade", pode-se imaginar que ele está diretamente ligado à relação existente entre muitos textos. Kristeva $(1974$, p. 64) confirma essa idéia quando afirma que todo o texto é absorção e transformação de um outro texto.

Diante dessa confirmação se pode dizer que um texto é a continuação de outro; ou ainda, que um texto pode ser elaborado a partir das idéias de diversas produções textuais. Percebe-se um ar de diálogo entre os textos. Para Nitrini (2000, p. 36), a intertextualidade se insere numa teoria totalizante do texto, englobando suas relações com o sujeito, o inconsciente e a ideologia, numa perspectiva semiótica.

Isto revela que o autor de um intertexto trabalha em âmbito externo, quando focaliza o tópico em discussão, mas também em âmbito interno, quando, até involuntariamente, discorre a partir de suas vivências, de suas sensações sobre o assunto. $\mathrm{O}$ "conhecimento de mundo" tanto do produtor como do receptor do texto é um fator que deve ser compartilhado e é o que, com certeza, fará com que ambos se entendam, já que, segundo Remédios (2005, p. 135), a leitura linear é substituída 
por uma leitura de correlações, pois o texto se apresenta como o ponto de intersecção de diferentes extratos que vêm dos diferentes horizontes.

Ainda segundo a autora (2005, p. 134) no texto literário, a noção de intertextualidade conduz à idéia de intersecção de textos e discursos, instituintes e instituidores de formações discursivas e suas respectivas condições de produção. Assim dizendo, a intertextualidade permite a emersão das vozes de outros textos, os quais são utilizados como referência na produção literária intertextual.

A produção intertextual é cotidiana. Nem sempre se tem consciência dessa prática, mas ela aparece tanto nos textos escritos como falados. Sempre que se produz um texto, se agregam idéias já ditas a este novo; assim também quando alguém relata um fato, já contado por outro: alguns detalhes são mantidos, outros inventados. Para Remédios (2005, p. 134-135) o texto é sempre apresentado com várias dimensões, significando a expressão pluri:

\begin{abstract}
Quando a criação intertextual é declarada, imputa-se ao conceito de texto toda a concepção de linguagem caracterizada pela não-linearidade, pela nãoseqüencialidade, enfim, pela dispersão textual, como acontece na linguagem cibernética. Assim, concebem-se as possibilidades da intertextualidade pela própria idéia de leitura e de escrita como pluritextualidades, uma vez que escrita e leitura consomem-se nas associações que constroem e desconstroem regularmente, recombinando códigos e suportes com particular interesse no que diz respeito à própria condição dos gêneros literários.
\end{abstract}

Portanto, todo o texto se concretiza a partir da reunião de fragmentos de outros textos. Até mesmo as descobertas inéditas da ciência, por exemplo. As mesmas perpassaram outras pesquisas até que se chegasse a um resultado único. Assim também se desenvolve o texto literário, permitindo que outros falem, dando espaço para manifestações críticas, mas, sobretudo, procurando manter as características de uma urdidura ficcional.

\title{
CONCEITOS EM PRÁTICA: NOVAS VERSÕES DE ROMEU E JULIETA
}

Muito se discute sobre o ato de parodiar, porém, não há nada mais proveitoso do que proporcionar o desenvolvimento dessa atividade. Os resultados são a confirmação de tudo o que se afirma acerca do tema. Para bem exemplificar o fato, se pode citar a proposta de aula desenvolvida entre os alunos do terceiro ano, já identificados na introdução deste trabalho.

A tarefa se iniciou com a leitura, discussão e levantamento dos principais temas enfatizados na síntese da obra Romeu e Julieta, de William Shakespeare; a seguir se debateu sobre os aspectos que tangem a produção de uma paródia, ficando claro que os alunos apresentavam um entendimento satisfatório sobre o assunto. As paródias foram desenvolvidas e, por fim, a turma assistiu ao filme Shakespeare in love (Shakespeare apaixonado), que relata mais detalhes sobre o trabalho do autor e caracteriza o teatro da era elisabetana. 
Ao término do desenvolvimento dessa atividade, os estudantes apresentaram paródias que ratificam os conceitos debatidos nesse trabalho. A base da tragédia foi mantida, porém, cada aluno-escritor imaginou cenas e ambientes caracterizados a partir de seu meio social. Percebeu-se uma rede de praticidade nos textos masculinos e um emaranhado de ilusão e romance nos femininos.

Em mais uma de suas definições, Hutcheon (1989, p. 109) caracteriza a paródia como que a confirmar o que se verificou nos textos da turma:

A paródia é uma das técnicas de auto-referencialidade por meio das quais a arte revela a sua consciência da natureza do sentido como dependente do contexto, da importância da significação das circunstancias que rodeiam qualquer elocução.

Assim, percebe-se de maneira clara o desvelar do subjetivo de cada aluno parodiador. Alguns exibiram, sem receios, sua visão de mundo, do amor, do proibido. Outros preferiram velar sua posição, provavelmente uma autocensura, provocada pelo instinto pessoal de proteção moral.

\section{COTEJAMENTO ENTRE TEORIA E PRÁTICA E CONTEXTO DE APLICAÇÃO}

Vê-se que a paródia é um tema que permite um estudo ainda mais aprofundado, o que é desenvolvido constantemente pelos teóricos da área. No entanto, é possível afirmar que o conceito que já se tem sobre a mesma é suficiente para que ela seja praticada e tida em sala de aula como instrumento comprovado de manifestação do imaginário criativo dos educandos. Ela promove a liberdade de expressão, a possibilidade da inserção do meio e facilita a fala das muitas outras vozes que cada aluno traz consigo.

Para tanto, a experiência foi desenvolvida com uma turma de alunos do $3^{\circ}$ ano do Ensino Médio, da E.E.E.M. José de Anchieta, do município de Panambi, no segundo semestre letivo do ano de 2007. Apesar de a turma ser pequena (09 meninas e 04 meninos) muito se pôde observar através da leitura dos textos produzidos, por isso percebe-se que, de forma geral, as produções apresentam um ar de romance, de um amor verdadeiro que supera todas as barreiras. A tragédia não é mais o ponto forte. Ela é usada como uma estratégia de comoção, já que as produções foram elaboradas a fim de contemplar aspectos sociais da atualidade.

Notou-se que alguns educandos deixaram muitas de suas vivências interferir em suas produções. Não recearam em expor sonhos de amor completo e possível. As separações não seguiram com rigor Romeu e Julieta, pois grande parte dos alunos preferiu acreditar que estando vivos, os protagonistas poderiam, um dia, reatar. Não faltaram também histórias marcadas por exageros e demonstração velada de determinados preconceitos sociais, ainda incutidos na personalidade dos alunos.

Vê-se portanto, que a produção de paródias permitiu a esse grupo a desvinculação da produção textual engessada. Os alunos, a exemplo de Hutcheon (1989, p. 108), lançaram um olhar crítico e diferenciador ao passado artístico inerente à obra parodiada, presenteando o leitor com relatos absolutamente contemporâneos. 


\section{CONSIDERAÇÕES FINAIS}

Ao longo da execução desse trabalho, os objetivos apontados inicialmente foram discutidos e analisados. Levando-se em consideração todos os aspectos levantados, é possível afirmar que tanto a utilização da paródia como da intertextualidade beneficia claramente a capacitação textual do alunado.

Quando desafiados a parodiar uma das peças mais conhecidas de Shakespeare, os estudantes perceberam poder ousar, ir além do que ora fora instituído pelo autor. Notou-se, no entanto, que apesar de as versões respeitarem a genialidade do escritor, conseguiram revelar a opinião, bem como as vivências sociais de cada produtor.

Shakespeare, em sua tragédia, aborda temas universais e latentes. Porém, o resultado final das paródias nos permite confirmar os debates teóricos que tangem o desenrolar desse trabalho. Pode-se mesmo perceber uma "sobrecarga de significado" nas frases dos textos. Os alunos reinventaram a história para dizer o que pensavam sobre a mesma.

Conclui-se que a intertextualidade está inerente ao processo de escrita e que a paródia deveria ser mais utilizada no ambiente escolar. Esses instrumentos de produção permeiam a necessidade de possibilitar mais liberdade ao imaginário dos alunos, capacitá-los à criação, ao desenvolvimento ficcional, ou mesmo, à expressão concreta da crítica.

Convém lembrar, enfim, que muito do que se espera dos discentes acontece em função da importância e do esforço deferido pelos seus mestres à tarefa de incentivá-los a pensar. E é justamente aí que está o elo entre literatura, arte e sociedade: o professor deve proporcionar espaço para contestações e não ter medo de trilhar novos caminhos, já que o ponto de chegada, nestes casos, é incerto.

\section{REFERÊNCIAS BIBLIOGRÁFICAS}

ALVES, José Edil de Lima. A paródia em novelas - folhetins camilianas. Lisboa, Instituto de Cultura e Língua Portuguesa, 1990.

CARVALHAL, Tania Franco. Literatura comparada. São Paulo:Ática, 1998.

DUARTE, Rosália. Cinema e educação. Belo Horizonte: Autêntica, 2002.

HELIODORA, Bárbara. Falando de Shakespeare. São Paulo: Perspectiva, 1998.

HUTCHEON, Linda. Uma teoria da paródia. Lisboa: Edições 70, 1989.

KRISTEVA, Júlia. Introdução a semanálise. São Paulo: Perspectiva, 1974.

MAGALDI, Sábato. Iniciação ao teatro. 7. ed. São Paulo: Ática, 2000.

MADDEN, John. Shakespeare apaixonado (Shakespeare in love). Universal Pictures, 1998. DVD.

NITRINI, Sandra. Literatura comparada: história, teoria e crítica. 2.ed. São Paulo: EDUSP, 2000.

REIS, Carlos. O conhecimento da literatura. Introdução aos conhecimentos literários. 2. ed. Coimbra: Livraria Almedina, 1997. 
REMÉDIOS, Maria Luiza Ritzel. Literatura portuguesa: textualidade e intertextualidade. In: ORMEZZANO, Graciela; BARBOSA, Marcia Helena S. (org.). Questões de intertextualidade. Passo Fundo: Editora Universidade de Passo Fundo, 2005.

SHAKESPEARE, William. Romeu e Julieta. Tradução Beatriz Viégas Faria. Porto Alegre: L\&PM, 2006. 